Nota

\title{
La noticia de Rufino sobre Gregorio Taumaturgo en su traducción de la Historia Eclesiástica de Eusebio de Cesarea
}

\author{
Enrique Contreras \\ Monasterio Los Toldos, Argentina
}

Muy escasa ha sido la atención prestada a este breve texto de Rufino de Aquileya. Tal vez, por tratarse de una inserción dentro de una versión latina de mayor amplitud, como fue el caso de su traducción de la Historia Eclesiástica de Eusebio. $\mathrm{Y}$, sin embargo, como muy bien lo ha señalado Pierre Maraval en fecha reciente, es el primer escrito en latín sobre el Taumaturgo posterior al Elogio que le dedicó Gregorio de Nisa ${ }^{1}$. Aunque de poca extensión, resulta sumamente interesante la noticia que ahora presentamos, cuanto menos por la inserción de la Confesión de fe del santo obispo.

Rufino de Aquilea, Sobre la vida de Gregorio Taumaturgo ${ }^{2}$

\section{INTRODUCCIÓN}

Pero ya que el texto de la historia hizo mención del bienaventurado Gregorio, considero muy apropiado insertar en esta narración hechos de tan gran hombre, que se celebran en boca de todos bajo el cielo oriental y septentrional, omi-

1 En su Introduction a la edición del Elogio de Gregorio Taumaturgo de Gregorio de Nisa, Sources chrétiennes, 573, Paris, Eds. du Cerf, 2014, 37.

2 Traducción del Lic. Julián Matías S. D’Avila, a partir de la edición de Theodor Mommsen: Eusebius Werke. Zweiter Band. Die Kirchengeschichte, Leipzig, J. C. Hinrichs'sche Buchhandlung, 1908, pp. 953-956 (Die griechischen christlichen Schriftsteller der ernsten drei Jahrhunderte, 9/2). Notas de J. M. S. D’Avila y E. Contreras. Los números y los subtítulos no figuran en el texto latino. 
tidos por no sé qué azar, para memoria de la posteridad ${ }^{3}$.

\section{EL LAGO DESECADO}

En las inmediaciones del Ponto había cierta laguna abundante en peces, de cuya captura se obtenían enormes ganancias para los dueños. Esta posesión les había tocado como herencia a dos hermanos. Pero el deseo de dinero, que vence los corazones de casi todos los mortales, también violentó el vínculo fraternal. En la temporada de pesca, los hermanos rivalizaban no tanto para capturar peces como para embaucar hombres ${ }^{4}$, se promovían matanzas y guerras, se derramaba sangre humana por peces. Pero por la providencia de Dios se presentó cierta vez la llegada y el auxilio ${ }^{5}$ de Gregorio. $\mathrm{Ve}^{6}$ batallas y muertes de hombres, y hermanos furiosos; pregunta cuál era la causa de que se enardecieran hasta la muerte propia y de sus hermanos, no descubre ninguna sino la captura de peces. Entonces, como ambas partes hubieran callado un momento por respeto a su llegada, dice: "Oh hijitos, no violenten almas racionales por animales mudos, no disuelvan la paz fraterna por el deseo de ganancia, no violen a la vez las leyes de Dios y el derecho de la naturaleza, y vengan juntos conmigo a la orilla de la mortífera laguna. Ya mismo, por la virtud del Señor, yo los libraré de toda lucha sangrienta ${ }^{7}$. Y, habiendo

3 Los hechos que narrará Rufino tienen otra versión, más amplia, en el Elogio de Gregorio el Taumaturgo compuesto por Gregorio de Nisa (cf. PG 46, cols. 893-958; y SCh 573, pp. 94-227, que reproduce la edición del texto griego efectuada por Günther Heil, De vita Gregorii Thaumaturgi, Leyde, Brill, 1990, pp. 1-57 [Gregorii Nysseni opera, $\mathrm{X}, 1]$ ).

4 En latín hay un juego etimológico de palabras entre captio, capiendos y decipiendos. Captio, traducido aquí como "pesca", significa a la vez "captura" y "engaño"; estos dos significados se desdoblan en ad pisces capiendos "para capturar peces" y ad homines decipiendos "para embaucar hombres". Al traducirlo preferimos mantener la claridad de significado por sobre la reproducción del recurso literario.

5 En latín hay una figura literaria llamada hýsteron próteron ("lo último primero"), que consiste en invertir el orden de las acciones: auxilium adventusque 'el auxilio y la llegada'. No la reproducimos en la traducción.

6 La falta de coherencia de los tiempos verbales está en el texto latino. Hemos decidido no "mejorarlo" en este aspecto.

7 Literalmente "de toda disputa de lucha sangrienta" (omni certamine cruentae contentionis). Omitimos una palabra para evitar redundancia. 
dicho esto, a la vista de todos clava sobre las primeras olas de la costa el báculo que tenía en la mano $y$, arrodillándose, tiende las palmas al cielo y suplica con estas palabras al excelso Dios: «Tú, Señor Dios de nuestros padres, quien, cuando Adán, el primer hombre, pecó contra ti y desobedeció tu mandato, habiendo moderado la pena de su culpa desviaste hacia la tierra la sentencia de maldición diciendo: "Maldita la tierra en tus obras" (cf. Gn 3,17), también ahora, pues, compadecido de la sangre fraterna de estos jóvenes, que está en peligro, ordena que estas aguas sean malditas en las obras de estos por los cuales, inflamados de furia, se han olvidado del respeto fraterno, de modo que nunca en este lugar aparezca un pez o se asiente el agua, sino que sea un campo paciente del arado y fértil en mieses, y persevere eternamente como custodio de la concordia fraterna». Ni bien terminó de orar, el agua, hundiéndose y huyendo en una corriente muy veloz, puesto que se le había ordenado apartarse de la vista superior, regresa a sus abismos y deja un campo seco a los hermanos ya reconciliados. Y se dice que hasta el día de hoy es un suelo fértil en mieses el que antes había sido fértil en barcos.

\section{LA ROCA DESPLAZADA}

También se recuerda otro hecho suyo, más ilustre y divino. Como en cierto lugar de terreno estrecho la situación demandara construir una iglesia, negaban el espacio suficiente para ella una roca de un monte cercano enfrentada por el este y un río que corría por el otro lado. Y, como no hubiera otro lugar en absoluto y todos estuvieran tristes porque no tenían solar para levantar la iglesia, él -se dice- pasó la noche en oración lleno de fe y recordó fielmente al Señor Jesús su promesa en la que dijo: «Si tuvieran la fe como un grano de mostaza, le dirían a este monte: "Levántate y arrójate en el mar", y así se haría (Mt 17,20; 21,21)». Y habiendo rogado esto con plena fe y devoción, cuando al amanecer se reunieron los pueblos, se halló que la roca inoportuna había retrocedido tanto espacio como se pedía para poner los cimientos de la iglesia.

\section{GREgorio pASA LA NOCHE EN UN TEMPLO PAGANO, LA CARTA PARA APOLO, LA CONVERSIÓN DEL SACERDOTE DE APOLO}

Se cuentan también muchos otros [hechos] de él, pero para que no parezca que extendemos demasiado el asunto, añadiré un hecho más a los intercalados. Se dice que 
cierta vez hizo un viaje por los $\mathrm{Al}$ pes en época de invierno y, habiendo llegado a lo más alto de las montańas alpinas, todo estaba repleto de nieve y no había ningún refugio allí, solo un templo de Apolo, en el cual se hospedó y, pasada la noche, se fue. Pero estaba cierto sacerdote del templo, quien acostumbraba consultar a la estatua de Apolo y transmitir las respuestas a quienes las demandaban, de lo cual parecía que obtenía también su sustento ${ }^{8}$. Así, por tanto, después de la marcha de Gregorio, el sacerdote fue a ofrecer consultas y pedir respuestas según su costumbre, desde allí no venía ninguna respuesta. Vuelve a ofrecer víctimas, continúa el silencio. Sacrifica una y otra vez, cuenta un cuento a los sordos?. Y como, ante el estupor de un nuevo silencio, el sacerdote se inquietara, de noche el demonio, de pie junto a él, le dice en sueños: “¿Por qué me invocas adonde ya no puedo venir?". Al [sacerdote] que preguntaba la causa le decía que había sido expulsado por la llegada de Gregorio. Como [el sacerdote] preguntara qué solución le daría ahora, dice que no le está permitido entrar en el lugar a menos que Gregorio lo autorice. Habiendo oído estas cosas, el sacerdote toma ${ }^{10}$ el camino, revolviendo muchos pensamientos en sí mismo y examinándolos con ánimo de protesta. Llega hasta Gregorio y, abordándolo, expone el asunto ordenadamente, le recordó su amabilidad y hospitalidad, expone la queja por el espíritu expulsado, se lamenta porque se le ha quitado su medio de vida, y demanda que todo le sea regresado al estado original. Él, sin demora, escribe una esquela con estas palabras: "Gregorio a Apolo. Te permito regresar a tu lugar y hacer lo que solías". Toma el sacerdote esta carta y la lleva al templo, y puesta junto a la estatua se hizo presente el demonio y dio respuestas al que las pedía. Entonces aquel, vuelto hacia sí, dice: "Si Gregorio ha ordenado y este dios se marchó, y no podía

8 Ex quo ei etiam alimoniae quaestus esse videbatur, lit. "de lo cual parecía que también había para él una ganancia de sustento". Simplificamos la frase latina para lograr mayor claridad de expresión en español.

9 Dicho popular. Para su presencia en la literatura latina, cf. Terencio, Heautontimorumenos, 222 (Surdo narrare fabulam: contar una historia a un sordo); Virgilio, Bucólicas 10,8 (non canimus surdis: no cantamos para sordos); Horacio, Epistolas, II, I, 999 ("hablaban a un jumento sordo"); Propercio, Poemas IV,8,47 (cantabant surdo: cantaban a un sordo).

10 Lit.: ocupa (occupat). 
regresar si no se lo ordenaban, y al ordenarlo Gregorio nuevamente fue restituido, ¿cuánto mejor es Gregorio que este, que obedece sus órdenes?”. Así pues, cerradas las puertas del templo, desciende hasta Gregorio volviendo a llevar consigo la carta que había tomado y, exponiéndole todo el orden del hecho, $\mathrm{y}$ postrándose simultáneamente a sus pies, le ruega ofrecerse a aquel Dios por cuya virtud Gregorio mandaba sobre los dioses paganos. Y, como persistiese con mucho esfuerzo y tesón, fue hecho catecúmeno por él. Y como, tras haber abandonado todos los errores de los demonios y las actividades del siglo, se entregara a una vida de mucha castidad y abstinencia, también consiguió el bautismo. Y avanzó tanto en mérito de vida y virtud de fe,

\section{Texto latino de Rufino}

Un (solo) Dios,

Padre del Verbo viviente,

de la sabiduría subsistente y de su poder y figura, que él mismo quedó como sucesor del bienaventurado Gregorio en el episcopado.

\section{LA CONFESIÓN DE FE DE GREGORIO MÁRTIR Y OBISPO DE NEOCESAREA ${ }^{11}$.}

Pero también nos dejó los mayores monumentos de su talento en lo pequeño. En efecto, el mismo Gregorio escribió magníficamente una metáfrasis del Eclesiastés y dejó una exposición de la fe católica declarada brevemente, que juzgué útil unir a estos relatos para edificación de las Iglesias. Para mostrar la correspondencia con el texto griego de esta confesión en el Elogio disponemos ambos pasajes en columnas paralelas ${ }^{12}$. En nota reproducimos el original de la confesión de fe en el Elogio.

Texto griego del "Elogio" (\$ 32) de Gregorio de Nisa

Un solo Dios, Padre del Verbo viviente,

(que es) sabiduría subsistente, poder e impronta eternas (cf. Hb 1,3),

11 En el Elogio (\$ 31) de Gregorio de Nisa esta confesión le es revelada al Taumaturgo por el apóstol Juan.

12 Cf. PG 46, cols. 911-914; SCh 573, 136-139. 
perfecto que engendró al perfecto, Padre del Hijo unigénito. Un solo Dios del solo Dios, figura e imagen de la deidad,

Verbo que obra ${ }^{13}$ sabiduría que contiene $e^{14}$ todas las cosas,

y poder, por el que toda creatura pudo ser hecha,

Hijo verdadero del Verdadero, e invisible del invisible, e incorruptible del incorruptible, e inmortal del inmortal, y sempiterno del sempiterno.

Uno (solo) Espíritu Santo, teniendo la sustancia de Dios ${ }^{15}$ y que apareció por el Hijo,

imagen del Hijo perfecto, causa perfecta de los vivientes, santidad que da santificación, por el cual es conocido Dios (que está) sobre todas las cosas y en todas las cosas, y el Hijo por todos [es conocido].

La Trinidad perfecta no está modo alguno dividida ni separada por la majestad, la eternidad y el reino. perfecto progenitor del perfecto, Padre del Hijo único (o unigénito). Un solo Señor, único del único, Dios de Dios, impronta e imagen de la divinidad,

Verbo que obra sabiduría que abarca la disposición de todas las cosas

y poder creador de todas las criaturas,

Hijo verdadero del Padre verdadero, invisible del invisible incorruptible del incorruptible, inmortal del inmortal, eterno del eterno.

Un solo Espíritu Santo, que de Dios tiene la existencia y porque por medio del Hijo apareció evidentemente a los hombres, imagen perfecta del Hijo perfecto, vida, causa de los vivientes, santidad, dispensador ${ }^{16}$ de santificación, en el cual se ha manifestado Dios el Padre, que está sobre todas las cosas y en todo,

y Dios el Hijo, quien (está) a través de todas las $\operatorname{cosas}^{17}$.
13

14

16 El término griego es choregós, aplicado a Dios ya en 2 M 1,25, pero con otro sentido: "(Señor), Tú solo generoso".

Perpetrans.

Comprehendo.

Traducción literal de: Unus Spiritus Sanctus ex Deo substantiam habens.

$\mathrm{O}$ dià pánton. 
Así pues, nada creado ni servil ni sobreañadido (hay) en la Trinidad, como si no subsistiera antes de ella, sino que hubiera ingresado después.

Por lo tanto, ni faltó alguna vez el Hijo al Padre ni el Espíritu Santo al Hijo, sino que la misma Trinidad (es) siempre inconvertible e inmutable.
La Trinidad perfecta por la gloria, la eternidad, el reinado, no está dividida ni separada ${ }^{18}$.

Por tanto, nada creado ni servil (hay) en la Trinidad ni introducido desde fuera como si no existiera antes, sino que hubiera sido introducido después.

Por consiguiente, nunca (le) faltó el Hijo al Padre ni el Espíritu al Hijo, sino que la misma Trinidad es inmutable e invariable ${ }^{19}$.

Pero sobre Gregorio es suficiente con lo dicho. Volvamos ahora a la historia.

18 Apallotrioyméne: estar apartado, estar excluido.

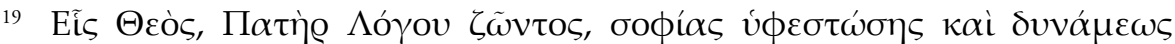

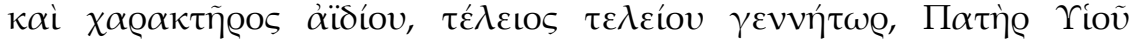

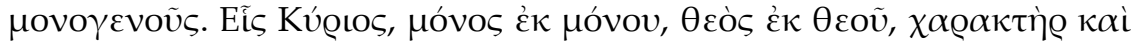

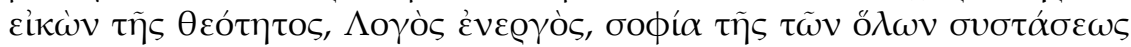

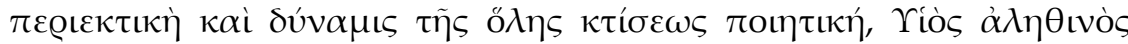

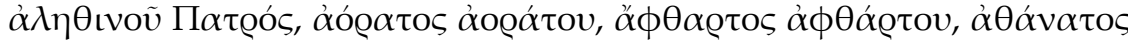

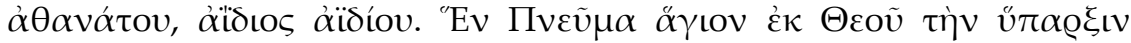

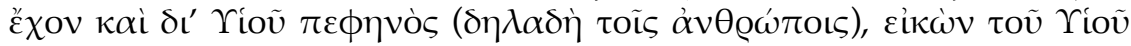

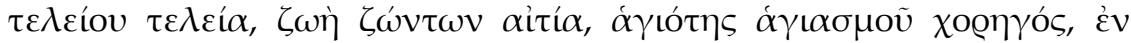

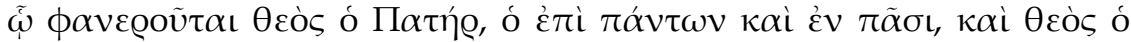

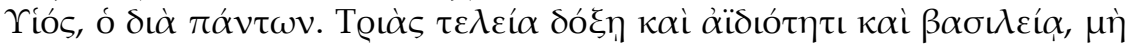

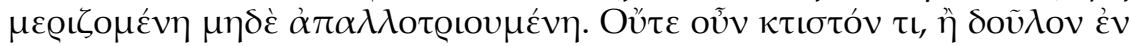

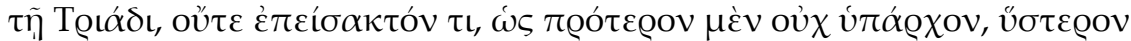

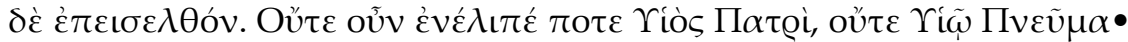

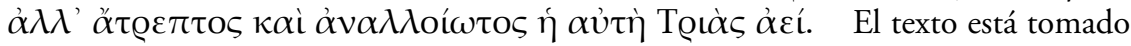
de Gregorio de Nisa, Sources Chrétiennes 573, 136-138, Elogio de Gregorio el Taumaturgo, 32 . 